\title{
Value of CA 15-3 in Female Patients with Breast Cancer
}

\author{
Shimaa A. Rashed, Osama B. Seddek, Hasnaa A. Abo-ELwafa and Abeer M. \\ Mohamed
}

\author{
Department of Clinical Pathology, Faculty of Medicine, Sohag University
}

\section{Abstract}

Introduction: Breast cancer (BC) is most common cancer site in women worldwide. The CA 15-3 is tumor associated antigen which detects soluble forms of MUC-1 protein. In normal breast tissue MUC-1 is expressed in the duct and acini, but with neoplastic transformation normal cell polarization and tissue architecture is disrupted leading to shedding of MUC-1 in the blood, where it can be measured by immunoassay. It is the most widely used serum marker in patients with BC. Its main use is for monitoring therapy in patients with metastatic disease.

Aim of the work: Aim of this work was to detect the diagnostic value of CA 15-3 in female patients with BC.

Patients and Methods: This study was carried on one hundred women, included fifty female patients with BC presented to Medical Oncology Department at Sohag University Hospital from 2015 to 2017, their age ranged from (25-70 years). Patients were diagnosed by clinical examination and confirmed by mammography and surgical biopsies; fine needle aspiration cytology (FNAC) or core needle biopsy (CNB) and CA15-3. Other fifty women were 25 healthy control not relatives to the patients and the other 25 were first degree relatives to the patients.

Results: Our study suggested that CA $15-3$ is abnormal in the majority of patients with breast cancer.

Conclusion: Serum markers in BC are helpful for clinicians in providing more effective management of the disease. To this end, different markers have been proposed in the last years. In particular, MUC1 (CA 15-3) is the most widely used and investigated in the breast cancer follow-up period.

Key words: CA 15-3, Breast Cancer.

\section{Introduction}

$\mathrm{BC}$ is most common cancer site in women worldwide. In Europe, 464,000 new breast cancer cases a year are detected in women $(13.4 \%$ new cancer cases in women) ${ }^{(1)}$. In Croatia, 25,574 new female cancer cases $(26 \%$ of total new female cancer cases) were recorded in 2013, and $994(16.8 \%)$ of total female deaths are caused by BC. Male BC is rare. The male breast cancer incidence is 1-2 in 100 cancer cases ${ }^{(2)}$.

Risk factors related to the $\mathrm{BC}$ development are numerous, including genetic, hormonal, nutritional and environmental.. Regardless of all available risk factor data, the said risk factors have not been confirmed in $75 \%$ women with $\mathrm{BC}{ }^{(3)}$. The most recent classification of invasive breast carcinoma based on biological characteristics includes: Luminal A, Luminal B, HER2 positive and triple-negative breast carcinoma ${ }^{(4)}$.

The CA $15-3$ is tumor associated antigen which detects soluble forms of MUC-1 protein. In normal breast tissue MUC-1 is expressed in the duct and acini, but with neoplastic transformation normal cell polarization and tissue architecture is disrupted leading to shedding of MUC-1 in the blood, where it can be measured by immunoassay. It is the most widely used serum marker in patients with BC. Its main use is for monitoring therapy in patients with metastatic disease. In monitoring therapy in this setting, CA 153 should not be used alone but measured in conjunction with diagnostic imaging, clinical history and physical examination 
(5) Healthy women are expected to have CA $15-3$ assay values below $30 \mathrm{U} / \mathrm{ml}^{(6)}$. The upper limit of the range varies depending on the laboratory and kit used for the test. The elevation of CA 15-3 (values over $120 \mathrm{kU} / \mathrm{L}$ ) is found in over $30 \%$ of BC patients with advanced disease (7). Serum CA 15-3 has been extensively studied mainly to monitor the response of $\mathrm{BC}$ to the treatment or to detect early relapse in BC follow-up. CA 15-3 may

\section{Aim of the work:}

Aim of this work was to detect the diagnostic value of CA 15-3 in female patients with Breast Cancer.

\section{Patients and Methods:}

\section{Patients:}

This study was carried on one hundred women, included fifty female patients with BC presented to Medical Oncology Department at Sohag University Hospital from 2015 to 2017, their age ranged from (25-70 years). Patients were diagnosed by clinical examination and confirmed by mammography and surgical biopsies; fine needle aspiration cytology (FNAC) or core needle biopsy (CNB) and CA15-3. Other fifty women were 25 healthy control not relatives to the patients and the other 25 were first degree relatives to the patients.

All subjects enrolled in this study signed a written informed consent. Ethical approval was obtained from the Ethical Committee of the Faculty of Medicine.

\section{Methods:}

All groups were subjected to the following:

\section{History taking including:}

- Age and menstrual status.

- Family history of breast cancer.

- Clinical presentation.

- Marital status.

- Parity and lactation.

- Time of diagnosis and status of treatment. also be used in the postoperative surveillance of asymptomatic women who have undergone surgery for invasive breast cancer. In this setting, serial determination can provide median lead-times of 5-6 months in the early detection of recurrent/metastatic breast cancer. It is unclear however, whether administering systemic therapy based on this lead-time improves patient outcome ${ }^{(7)}$.

2. Clinical examination including careful examination of the breast and the axillary lymph nodes.

ONLY the patient groups (Group I \& GroupII) were subjected to:

3. Mammography: To confirm presence of breast mass.

4. FNA biopsy or CNB: Followed by pathological examination to confirm the presence of malignancy.

5. Metastatic work up:

- Chest X ray and/or CT scan.

- Bone scan.

Laboratory Investigations:

Sample Collection:

$10 \mathrm{ml}$ of venous blood was withdrawn into three vacutainer tubes were taken through venipuncture under a complete aseptic technique.

a. The first tube contains two $\mathrm{ml}$ of blood on EDTA (Ethylene diaminetetra acetic acid) purple capped vacutainer tube for CBC (Complete Blood Count), ESR (Erythrocyte sedimentation rate).

b. The second one contains five milliliters of blood on plain red capped vacutainer tube, after clotting; the serum was separated by centrifugation for 10 minutes at 4,000 rpm and then was used for assessment of routine chemistry tests (RFT, LFT, and CA153). 
6. Specific Investigations:

A-CA 15-3 Assay:

By chemiluminescent microparticle immunoassay (CMIA) method for the

\section{Results}

The mean age in $\mathrm{BC}$ group was 48.68 with SD 12.30 years with range 29-68 years which was older than control group as its mean age was 42.96 with SD 14.0 years with range 24-68 years, with non-significant difference.

The mean age of menarche in BC group was 12.00 with SD 1.803 years with range also 9-15 years which was non significant different from mean age of menarche in control group as it was 12.19 with SD 1.32 years with range 10-15 years. There was high significant difference ( $\mathrm{p}$ value $<0.001$ ) between the studied groups as regards parity. Majority of BC cases (68\%) had 4 children; however $44 \%$ of controls were singles.

\section{Association between different reproductive factors and BC:}

None of different reproductive factors enrolled in the present study was significantly associated with the occurrence of breast cancer except the marital state. There was significant difference between $\mathrm{BC}$ and controls according to marital state. There was significant increase of married patients in $\mathrm{BC}(96 \%)$ but in controls $(56 \%)$ (p value $<0.001)$.

There was non-significant difference between groups regarding use of contraception, $52 \%$ of BC group and only $32 \%$ of controls were using contraception. There was also non-significant difference between groups regarding menopausal state, 52\% of BC group were premenopausal but controls included 64\% premenopausal.

There was also non-significant difference between groups regarding breastfeeding, $76 \%$ of BC group and only $56 \%$ of controls were breast feed (Table 1).

Table 1. Distribution of studied groups according to marital state, use of contraception, menopausal status and breast feeding

\begin{tabular}{|c|c|c|c|c|c|}
\hline \multirow{2}{*}{\multicolumn{2}{|c|}{ Reproductive factors }} & \multirow{3}{*}{$\begin{array}{l}\text { BC } \\
\text { No. }(\%) \\
24(96 \%)\end{array}$} & \multirow{3}{*}{$\begin{array}{l}\text { Control } \\
\text { No. }(\%) \\
14(56 \%)\end{array}$} & \multirow{3}{*}{ Chi square } & \multirow{3}{*}{$P$ value } \\
\hline & & & & & \\
\hline \multirow[t]{2}{*}{ Marital state } & Married & & & & \\
\hline & Single & $1(4 \%)$ & $11(44 \%)$ & 18.000 & $<0.001$ (HS) \\
\hline \multirow[t]{2}{*}{ Use of contraception } & Yes & $13(52 \%)$ & $8(32 \%)$ & \multirow[b]{2}{*}{4.167} & \\
\hline & No & $12(48 \%)$ & $17(68 \%)$ & & 0.244 (NS) \\
\hline \multirow[t]{2}{*}{ Menopausal status } & Pre & $13(52 \%)$ & $16(64 \%)$ & \multirow[b]{2}{*}{4.478} & \multirow[b]{2}{*}{$0.214(\mathrm{NS})$} \\
\hline & Post & $12(48 \%)$ & $9(36 \%)$ & & \\
\hline \multirow[t]{2}{*}{ Breast feeding } & Yes & $19(76 \%)$ & $14(56 \%)$ & \multirow[b]{2}{*}{2.242} & \multirow[b]{2}{*}{$0.524(\mathrm{NS})$} \\
\hline & No & $6(24 \%)$ & $11(44 \%)$ & & \\
\hline
\end{tabular}

As regards site of tumor, $72 \%$ of BC group had unilateral tumor and only $28 \%$ of had bilateral tumor. 
There were only 3 cases $(12 \%)$ of $\mathrm{BC}$ group had metastases. There was nonsignificant difference between $\mathrm{BC}$ and controls as regards $\mathrm{CBC}$ (WBCs, HB, PLTs) when compared to controls.

There was high significant difference ( $\mathrm{p}$ value $<0.001)$ between groups as regards ESR as $100 \%$ of BC group had high ESR and none of control group had high ESR.

There was non-significant difference between $\mathrm{BC}$ and controls as regards liver function tests which include alanine aminotransferase (ALT), aspartate aminotransferase (AST), total protein, albumin, total bilirubin (TBIL), direct bilirubin (Direct BIL) and alkaline phosphatase (ALP) when compared to controls. On the other hand, there was high significant increase in urea in $\mathrm{BC}$ group when compared to controls ( $p$ value $<0.001$ ), also there was significant increase in creatinine in BC group when compared to relatives and controls ( $\mathrm{p}$ value $=0.02$ ).

\section{Specific investigations.}

\section{CA 15-3}

There was high significant increase in CA 15-3 in BC group when compared to controls ( $\mathrm{p}$ value<0.001) (Table 2).

Table 2. CA 15-3 of the studied groups.

\begin{tabular}{ccccc}
\hline & $\begin{array}{c}\text { BC } \\
\text { group } \\
\text { Mean } \pm \text { SD }\end{array}$ & $\begin{array}{c}\text { Control group } \\
\text { Mean } \pm \text { SD }\end{array}$ & ANOVA & P value \\
\hline $\begin{array}{c}\text { CA 15-3 } \\
(\mathbf{U} / \mathbf{m l})\end{array}$ & $201.08 \pm 131.6$ & $12.08 \pm 2.87$ & $33.807^{*}$ & $<\mathbf{0 . 0 0 1}$ (HS) \\
& & & & \\
\hline
\end{tabular}

\section{Discussion}

The mean age in BC group was 48.68 with SD 12.30 years with range 29-68 years which was older than control group as its mean age was 42.96 with SD 14.0 years with range 24-68 years, with non-significant difference.

In our study, the mean age of menarche in BC group was 12.00 with SD 1.803 years with range also 9-15 years which was non-significant different from mean age of menarche in control group as it was 12.19 with SD 1.32 years with range $10-15$ years.

In study of Knudson. ${ }^{(8)}$ They found that young age of menarche (before 13 years) was found to be associated with increased hazard of $\mathrm{BC}$ especially in susceptible women. This may be related to a higher life time exposure to the hormones estrogen and progesterone.

Our results were similar to results of Jalkh et al. ${ }^{9}$ as mean age in their study at diagnosis of $\mathrm{BC}$ for the seventy-two patients was 41 years old. In study of Peto et al. ${ }^{(10)}$ fifteen $(5.9 \%)$ of 254 women diagnosed with breast cancer before age 36 years and $15(4.1 \%)$ of 363 females diagnosed from ages 36 years through 45 years.

In this study there was high significant difference $(\mathrm{p}$ value $<0.001)$ between the studied groups as regards parity. Majority of BC cases $(68 \%)$ had 4 children; however $44 \%$ of controls were singles.

In this study none of different reproductive factors enrolled in the present study was significantly associated with the occurrence of $\mathrm{BC}$ except the marital state. There was significant difference between $\mathrm{BC}$ and controls according to marital state. There was significant increase of married patients in BC $(96 \%)$ than controls $(56 \%)$ ( $\mathrm{p}$ value $<0.001)$.

We found that there was nonsignificant difference between groups regarding use of contraception, $52 \%$ of 
BC group, however only 32\% of controls were using contraception. There was also non-significant difference between groups regarding menopausal state, $52 \%$ of BC group were premenopausal but controls included $64 \%$ premenopausal.

In this study, there was nonsignificant difference between groups as regards routine laboratory investigations (WBCs, HB, PLTs, ALT, AST, T. protein, Albumin, T.Bil, Direct. Bil and ALP). However there was high significant difference between groups as regards both ESR and CA 15.3 as $100 \%$ of BC group had high ESR, and none of control group had high ESR. On the other hand, mean of CA 15.3 was higher in $\mathrm{BC}$ group $(190.40 \pm 124.7)$ than control group (12.08 \pm 2.87$)$.

The results presented in study of Vali et al. (11) also demonstrate correlation between the preoperative CA 15-3 marker levels and tumor size (less than $2.2 \mathrm{~cm}$ ). An average tumor size of the studied group was more than $2.2 \mathrm{~cm}$. The patients with tumor larger than average had statistically higher (preoperative) level of CA 15-3. The patients with tumor between 5 and 10 cm (T3 tumors) had statistically significantly higher CA 15-3 marker level. However, because of a small number of patients in the group ( 2 patients with T3 tumor and one patient

\section{Conclusion:}

Serum markers in BC are helpful for clinicians in providing more effective management of the disease. To this end, different markers have been proposed in the last years. In particular, MUC1 (CA 15-3) is the most widely used and investigated in the breast cancer follow-up period. Initial studies indicate that CA $15-3$ is abnormal in the majority of patients

with T4 tumor), the result is difficult to interpret. Also, testing of difference between $\mathrm{T} 1$ and $\mathrm{T} 2$ tumors with regard to CA 15-3 level has not shown statistical significance. Patients with N3 tumor had significantly higher values of CA 15-3 marker ${ }^{(11)}$. Results obtained by Park et al. and Moazzezy et al. are similar. In their study they established a correlation between CA 15-3 (and CEA) level and tumor size $(>5 \mathrm{~cm})$ and lymph node status (more than 4 nodes involved) ${ }^{(12,13)}$. Duffy et al. got the results showing a significantly higher CA 15-3 marker levels in patients with larger tumors and patients with positive lymph nodes, unlike the patients with N0 status (14). The same results were obtained by Park et al. in their study (12)

Ebeling et al. study shows that tumor size, lymph node status, histological grade and hormonal status are prognostically significant ${ }^{(15)}$. Duffy et al. have not established a correlation between the CA 15-3 level with estrogen positive or negative receptors (which corresponds with the results of this study). On the other hand, their obtained results, of CA 15-3 level, was significantly higher in patients aged 50 years and older, while in our study the difference in CA 15-3 levels in patients older/younger than 50 years of age was not statistically significant ${ }^{(14)}$.

with metastatic breast cancer and the antigen levels are correlated with changes in the clinical status of breast cancer patients. However, CA 15-3 is not recommended as screening tool in early detection for $\mathrm{BC}$, even though it remains an important asset to monitor the efficacy of medical therapies after surgery.

\section{$\underline{\text { References: }}$}


1.Ferlay J, Steliarova-Foucher E, Lortet-Tieulent J, Rosso S, Coebergh JW, Comber H, Forman D, Bray F. Cancer incidence and mortality patt erns in Europe: estimates for 40 countries in 2012. Eur J Cancer. 2013; 49:1374-403.

2. Hrvatski zavod za javno zdravstvo. Registar za rak. Incidencija raka u Hrvatskoj 2013. Bilten 2015;38.

3. Gagnon, J., et al. "Recommendations on breast cancer screening and prevention in the context of implementing risk stratification: impending changes to current policies." Current Oncology 23.6 (2016): e615.

4. Vasconcelos, Ines, et al. "The St. Gallen surrogate classification for breast cancer subtypes successfully predicts tumor presenting features, nodal involvement, recurrence patterns and disease free survival." The Breast 29 (2016):18-185.

5. Duffy MJ, Evoy D, McDermott EW. CA 15-3: uses and limitation as a biomarker for breast cancer. ClinChim Acta. 2010 Dec 14;411(23-24):1869-74.

6. Nikhil G Thaker, Dolly R, Dina FC, Eric BS (2014): CA 15-3 reference range. emedicine Medscape article 2087491. 2014; 1-2.

7. Bast RC, Ravdin P, Hayes DF. Update of recommendations for the use of tumor markers in breast and colorectal cancer: clinical practice guidelines of the American Society of Clinican Oncology. J Clin Onc 2001; 19(6): 1865-78.

8. Knudson AG. Two genetic hits (more or less) to cancer. Nature reviews Cancer. 2001;1(2):157-62.

9. Jalkh N, Nassar-Slaba J, Chouery E, Salem N, Uhrchammer N, Golmard L, et al. Prevalance of BRCA1 and BRCA2 mutations in familial breast cancer patients in Lebanon. Hereditary cancer in clinical practice. 2012;10(1):7.

10.Peto J, Collins N, Barfoot R, Seal S, Warren W, Rahman N, et al .Prevalence of BRCA1 and BRCA2 gene mutations in patients with early-onset breast cancer. Journal of the National Cancer Institute. 1999;91(11):943-9.

11. Vali A, Ivan Milas, Ljiljana Mayer. Prognostic Significance Of Ca 15-3 Tumor Marker In Breast Cancer Patients. Libri Oncol. 2017;45(1):1-8.

12. Park BW, Oh JW, Kim JH, Park SH, Kim KS, Kim JH, Lee KS. Preoperative CA 15-3 and CEA serum levels as predictor for breast cancer outcomes. Ann Oncol. 2008;19:67581.

13. Moazzezy N, Farahany TZ, Oloomi M, Bouzari S. Relationship between preoperative serum CA 15-3 and CEA levels and clinicopathological parameters in breast cancer. Asian Pac J Cancer Prev. 2014;15(4):1685-8.

14. Duffy MJ, Duggan C, Keane R, Hill AD, McDermott E, Crown J, O’Higgins N. High preoperative CA 15-3 concentrations predict adverse outcome in node-negative

and node positive breast cancer: study of 600 patients with histologically confi rmed breast cancer. Clin Chem. 2004;50:559-63.

15. Ebeling FG, Stieber P, Untch M, Nagel D, Konecny GE, Schmitt UM, Fateh-Moghadam A, Seidel D. Serum CEA and CA 15-3 as prognostic factors in primary

breast cancer. Br J Cancer. 2002;86:1217-22. 